\title{
Aberrant chromatin remodeling in gynecological cancer (Review)
}

\author{
RYUICHIRO OKAWA, KOUJI BANNO, MIHO IIDA, MEGUMI YANOKURA, TAKASHI TAKEDA, \\ MOITO IIJIMA, HARUKO KUNITOMI-IRIE, KANAKO NAKAMURA, MASATAKA ADACHI, KIYOKO UMENE, \\ YUYA NOGAMI, KENTA MASUDA, YUSUKE KOBAYASHI, EIICHIRO TOMINAGA and DAISUKE AOKI
}

Department of Obstetrics and Gynecology, Keio University School of Medicine, Tokyo 160-8582, Japan

Received December 10, 2015; Accepted May 11, 2017

DOI: $10.3892 / 01.2017 .6891$

\begin{abstract}
Epigenetic regulatory mechanisms are a current focus in studies investigating cancer. Chromatin remodeling alters chromatin structure and regulates gene expression, and aberrant chromatin remodeling is involved in carcinogenesis. AT-rich interactive domain-containing protein 1A (ARID1A) and SWItch/sucrose non-fermentable-related, matrix-associated, actin-dependent regulator of chromatin, subfamily a, member 4 are remodeling factors that are mutated in numerous types of cancer. In gynecological cancer, ARIDIA mutations have been identified in $46-57 \%$ of clear cell carcinoma and $30 \%$ of endometrioid carcinoma. Mutations of chromodomain helicase, DNA-binding protein 4 have been detected in $17-21 \%$ of endometrial serous cancer, and mutations of ARIDIA and mixed-lineage leukemia 3 occur in 36 and $27 \%$ of uterine carcinosarcoma, respectively. These data suggest that aberrant chromatin remodeling is a potential cause of cancer, and have led to the development of novel proteins targeting these processes. Additional accumulation of information on the mechanisms of chromatin remodeling and markers for these events may promote personalized anticancer therapies.
\end{abstract}

\section{Contents}

1. Introduction

2. Chromatin remodeling

3. Aberrant chromatin remodeling and cancer

4. Chromatin remodeling-associated gene mutations and carcinogenic mechanism

5. Aberrant chromatin remodeling and ovarian cancer

6. Aberrant chromatin remodeling and endometrial cancer

Correspondence to: Dr Kouji Banno, Department of Obstetrics and Gynecology, Keio University School of Medicine, Shinanomachi 35, Shinjuku, Tokyo 160-8582, Japan

E-mail: kbanno@z7.keio.jp

Key words: chromatin remodeling, mutation, carcinogenesis, switch/sucrose non-fermentable complex, AT-rich interaction domain 1A, gynecological cancer
7. Therapy targeting aberrant chromatin remodeling

8. Conclusion

\section{Introduction}

Epigenetics involves the regulation of gene expression without a change in DNA sequence. Somatic cells retain and transfer epigenetic information based on DNA methylation, histone methylation, acetylation, ubiquitination, ADP ribosylation, histone modification, small RNAs unrelated to genetic codes and modification of chromatin structure through chromatin remodeling. The term 'chromatin remodeling' refers to the alteration of chromatin structure from a closed state to a loosened one, which is termed 'euchromatin' (1). There are a few types of chromatin remodeling complexes, including the SWItch/sucrose non-fermentable (SWI/SNF) complex, which has several subunits, including ARID1A and brahma homologue (BRM)-related gene 1 (BRG1; also referred to as SMARCA4) (2). Through the interaction between subunits, chromatin remodeling complexes change chromatin structure, and this determines gene expression levels via the regulation of the interaction between proteins with double-stranded DNA (3). This change in accessibility may be achieved by adenosine triphosphate (ATP)-dependent complexes modulating histone-DNA association and by covalent modification of core nucleosomal histones mediating the transcriptional activity (4). Epigenetics is also associated with intracellular communication (5). These are key events in cell growth, and thus epigenetic abnormalities may induce carcinogenesis, developmental defects and multifactorial disease. The association between aberrant chromatin remodeling with gynecological cancer is discussed in the present review.

\section{Chromatin remodeling}

In eukaryotes, almost all genomic DNA is packaged by core histones to form chromatin structures. These structures change in events such as transcription, replication, modification and recombination of genomic DNA (6). The requirement for different chromatin structures is fulfilled by chromatin remodeling, which is an important factor in the regulation of gene expression.

Chromatin remodeling is performed by two enzyme groups: Histone modifiers, which chemically alter histones; and ATP-dependent chromatin remodeling factors, which bind 
to nucleosome cores and surrounding DNA to change the chromatin structure. Using energy from ATP dephosphorylation, remodeling factors alter nucleosomal structure, transiently loosen binding with DNA, and coordinate with specific chaperones, exchanging specific or all nucleosome cores (4). The nucleosomal structure is dynamically changed by remodeling factors, resulting in prompt changes in the chromatin structure (6). Several types of ATP-dependent remodeling factors are known, including a number of high-molecular-weight protein complexes with $>10$ subunits (6). The activity of these complexes is regulated and they are transferred to specific DNA sites to regulate gene expression by changing the chromatin structure (6,7). ATP-dependent remodeling factors are classified into several families: SWI/SNF, imitation SWI (ISWI), INO80, SWR1, nucleosome remodeling deacetylase (NuRD)/Mi2/CHD and nucleosome remodeling factor (7).

\section{Aberrant chromatin remodeling and cancer}

Chromatin remodeling factors regulate epigenetic gene expression, and aberrations in this process may induce carcinogenesis. A large-scale study of genome sequences has identified mutations of genes encoding remodeling factors in a number of types of human cancer, including those for the SWI/SNF complex, which has led to the suggestion that SWI/SNF complexes are protective against cancer $(7,8)$. Mutations in SWI/SNF-related, matrix-associated, actin-dependent regulator of chromatin, subfamily a, member 4 (SMRCA4/BRG1), which encodes the ATPase subunit of the SWI/SNF complex, has been detected in $>30 \%$ of non-small cell lung carcinoma (NSCLC) (7). Similarly, mutations in the ARID1A, which encodes an additional subunit of the SWI/SNF complex, has been detected in $46-57 \%$ of clear cell carcinoma and $30 \%$ of endometrioid carcinoma in ovarian cancer (9). ARIDIA mutations also occur in $13 \%$ of hepatocellular carcinoma (HCC), $9.6 \%$ of gastrointestinal adenocarcinoma and $2.5 \%$ of malignant melanoma (7). Chromodomain helicase, DNA-binding protein 4 (CHD4), which forms the nucleosome remodeling and deacetylase (NuRD) complex, is overexpressed or mutated in serous endometrial cancer, and metastasis-associated protein 1 overexpression has been detected in breast cancer (10).

Deleted regions encoding mixed-lineage leukemia protein 3 (MLL3) produce chromosomal aberrations that are frequently associated with acute myeloid leukemia (AML) (11). Similar gene mutations are identified in medulloblastoma, HCC (12), bladder carcinoma (13), prostate cancer (14), colorectal cancer (15), gastric adenocarcinoma (16), NSCLC (17), breast cancer (18) and pancreatic cancer (19) and in AML (11). Je et al (20) revealed mutations causing a frameshift of MLL3 in $28.1 \%$ of cases of gastric cancer and $7.5 \%$ of cases of colon cancer.

\section{Chromatin remodeling-associated gene mutations and carcinogenic mechanism}

ARIDIA is located at $1 \mathrm{p} 35.3$ and encodes an $\sim 250-\mathrm{kD}$ protein that is involved in interactions between numerous proteins, including the SWI/SNF complex. The SWI/SNF complex has multiple activities, including the following: The promotion of binding of transcription factors, coactivators and compressors; mobilization of histone-modifying enzymes; promotion of binding of nucleosomes with promoter and enhancer regions; and promotion of chromatin loop formation to induce interactions of enhancers and promoters (Fig. 1) (7,21). The SWI/SNF complex and ARID1A also regulate transcription to induce steroid hormones: It has been suggested that ARID1A may be involved in recruiting SWI/SNF to regulate genes through its ability to stimulate steroid hormone receptor-mediated transcriptional activation (22,23). Wu and Roberts (21) proposed three activities of ARIDIA in the repression of tumors, namely, proliferation, differentiation and apoptosis. Gastrointestinal and breast cancer cells demonstrate a tendency to grow following $A R I D 1 A$-knockdown, and growth rates decrease subsequent to re-expression of ARIDIA. Ovarian epithelial cells and mouse preosteoblast cells indicated similar proliferation behaviors following ARIDIA-knockdown. With regard to differentiation, ARIDIA-knockdown eliminated self-renewal of ES cells and inhibited the differentiation of neurons and osteocytes in vitro. For apoptosis, the Fas apoptotic pathway in Jurkat cells was inhibited by knockdown of ARIDIA. These results demonstrate that an ARIDIA deficit has those three effects on tumor suppression (21). An ARIDIA deficit has also been associated with the activation of the phosphatidylinositol 3-kinase/protein kinase B (PI3K/AKT) signaling pathway, and with the amplification of zinc-finger protein 217 (ZNF217), which are involved in cancer development (24).

Dynamic regulation of chromatin structures to allow transcription factors to bind to DNA is necessary for gene transcription, duplication and repair. Two complexes, BRG1-associated factor (BAF) and polybromo-associated BAF (PBAF), in the SWI/SNF family, perform this role in eukaryotes (22). BRG1 and BRM are subunits containing ATPase domains that hydrolyze ATP to provide energy for translocation of nucleosomes and changes in chromatin structure (25). BRG1 binds to BRCA1 and regulates cluster of differentiation 44 expression as part of the epithelial-mesenchymal transition in cancer (25). BRGl (also referred to as SMARCA4) is located at p13.2 on the short arm of chromosome 19 (19p13.2). $B R G 1$ regulates DNA transcription and serves a role in tumor suppression due to remodeling of the chromatin structure. Therefore, mutations and deletions of this gene are identified in a number of cancer types, including ovarian small cell carcinoma, rhabdoid tumors (kidney and brain), medulloblastoma, lung adenocarcinoma, mantle cell lymphoma, Burkitt's lymphoma, HCC, esophageal adenocarcinoma, melanoma, non-melanoma skin cancer and intraductal papillary mucinous neoplasms of the pancreas (26).

Chromodomain helicase DNA-binding protein 4 (CHD4) is located on the short arm of chromosome 12 (12p13) and its transcription product is a molecule in the SNF2/RAD54 helicase family. CHD4 serves a key role in epigenetic transcription suppression, as it acts in nucleosome remodeling in an ATP-dependent manner, and is the major protein involved in the formation of a deacetylase complex. CHD4 exhibits tandem chromodomains in the $\mathrm{N}$-terminal region and an ATPase-helicase domain in the central region. The chromodomains recognize and bind to nucleosomes and regulate interactions with chromatin, whereas the ATPase-helicase domain is involved in DNA transcription, duplication, 


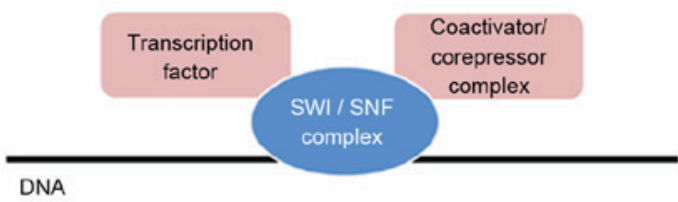

DNA

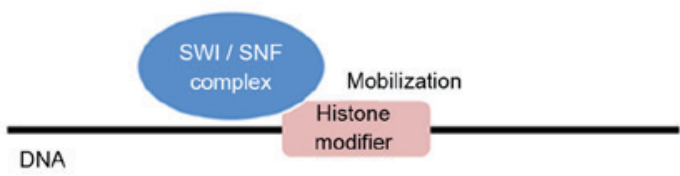

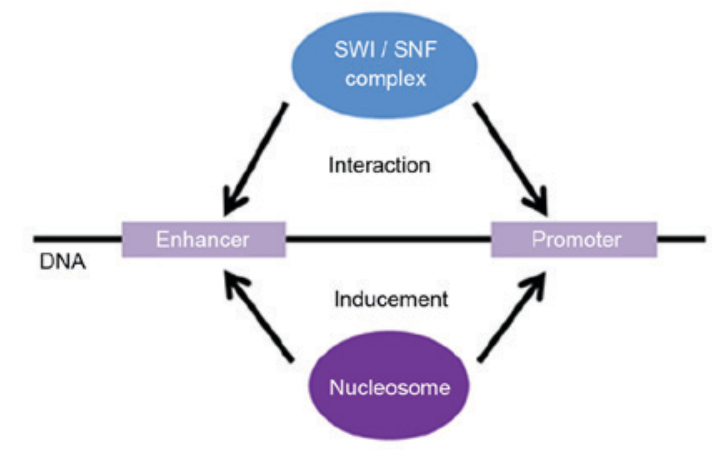

Figure 1. Actions of SWI/SNF complexes on chromatin structure that affect transcriptional regulation. The SWI/SNF complex recruits coactivator/corepressor complexes and transcription factors, and induces nucleosome formation at promoter and enhancer regions. The SWI/SNF complex also mobilizes histone-modifying enzymes and enhances interactions between enhancers and promoters. SWI/SNF, switch/sucrose non-fermentable complex.

recombination and repair (27). Mutations in these domains cause hyposegmentation in cells, indicating that the two domains are required for CHD4 function (27).

Mutations of $\mathrm{CHD}_{4}$ have been identified in several cancer types, and particularly in serous endometrial carcinoma: Zhao et al (28) revealed that $11 / 52$ patients exhibited a heterozygous somatic CHD4 mutation. Le Gallo et al (29) also identified a somatic mutation in $\mathrm{CHD} 4$ in $17 \%$ of patients with serous endometrial cancer. CHD4 is characterized by 'signature' motifs that contain important amino acid residues required for ATP hydrolysis and helicase activity. The normal function of CHD4 is eliminated by R957Q, R1127G and $\mathrm{R} 1162 \mathrm{~W}$ mutations in these residues (30). In an immunohistological examination of lesion tissues in gastric cancer and colorectal cancer, Kim et al (30) identified no CHD4 expression in $56.4 \%$ of patients with gastric cancer and $55.7 \%$ with colorectal cancer. Insertion or deletion of 1 to 2 bases caused a somatic mutation in $C H D 4$, with the resulting frameshift causing elimination of normal CHD4 expression (30).

MLL3 belongs to a gene cluster of the MLL family and is also called lysine N-methyltransferase 2C (KMT2C). MLL3 exhibits a histone methyltransferase SET domain, a HMG-binding domain, a nuclear receptor binding domain and 5 zinc fingers, and acts as a nuclear receptor coactivator in mammals (11). The MLL family transfers 1, 2 or 3 methyl groups to lysine K4 of methyl histone H3, and MLL3 particularly methylates $\mathrm{H} 3 \mathrm{~K} 4$ in enhancer regions (11). In a study of familial nasopharyngeal carcinoma, Sasaki et al (31) proposed that the mechanism of carcinogenesis involves the action of acquired factors such as somatic mutation and Epstein-Barr virus infection in regions containing germline mutations that frequently cause a stop codon in $M L L 3$. In an analysis of gene mutations in patients with Lynch syndrome, Villacis et al (32) also suggested that a MLL3 mutation increases the risk of colorectal cancer.

Enhancer of zeste 2 polycomb repressive complex 2 subunit $(E Z H 2)$ encodes proteins in the polycomb group (PcG) family and is located on chromosome 7 (7q35-q36). PcG proteins contribute to the epigenetic regulation of gene expression, for example: EZH2 methylates histone H3 core protein lysine 27 and inhibits gene transcription (33). EZH2 demonstrates high expression in numerous types of cancer, including breast cancer, melanoma and lung cancer (33). In gynecological cancer, high $E Z H 2$ expression occurs in uterine fibroids and cervical lesions. Yang et al (34) proposed a mechanism in which EZH2 inhibits the expression of the DNA mismatch repair gene Mutator $\mathrm{S}$ protein homolog 2 (MSH2) and develops uterine fibroids. Cai et al (35) revealed that $\mathrm{EZH} 2$ was expressed more frequently in cervical cancer tissues compared with normal tissues, and that cisplatin resistance in cervical cancer was increased by the inhibition of endogenous EZH2 expression with short hairpin RNA. Furthermore, an overexpression of $\mathrm{EZH} 2$ has been identified in $66 \%$ of tumors and $67 \%$ of endothelial cells of tumor vessels in patients with ovarian cancer (36). Patients with high expression of EZH2 in tumors exhibited a significantly poorer prognosis compared with those without high expression. The inactivation of $\mathrm{EZH} 2$ expression increases apoptosis of cancer cells, decreases the number of vessels in tumor tissues and reduces the growth of ovarian cancer cells (36).

\section{Aberrant chromatin remodeling and ovarian cancer}

Ovarian clear cell carcinoma (OCCC) is a chemoresistant cancer due to delayed cell division (37). OCCC exhibits two carcinogenic pathways, which are referred to as the adenofibroma-carcinoma and endometriosis-carcinoma sequences $(38,39)$. The differences in the genetic backgrounds of these two pathways are unclear, but the ARIDIA mutation has been suggested to be involved in the onset of OCCC via the endometriosis-carcinoma sequence, rather than via the adenofibroma-carcinoma sequence $(38,39)$. Jones et al (9) detected ARIDIA mutations in $24(57 \%)$ of 42 patients with OCCC, and concluded that ARIDIA is a tumor suppressor 
Table I. Aberrant chromatin remodeling-associated genes in cancer.

\begin{tabular}{|c|c|c|c|c|}
\hline Gene name & Mutation ratio, $\%$ & Gene abnormality & Type of cancer & (Refs.) \\
\hline \multirow[t]{7}{*}{ ARIDIA } & $46-57$ & MS, NS, FS & Ovarian clear cell carcinoma & (9) \\
\hline & 30 & MS, NS, FS & Ovarian endometrioid carcinoma & (2) \\
\hline & 13 & MS, NS, FS & $\mathrm{HCC}$ & (7) \\
\hline & 9.6 & MS, NS, FS & Gastrointestinal adenocarcinoma & (7) \\
\hline & 2.5 & MS, NS, FS & Malignant melanoma & $(7)$ \\
\hline & 36 & Mutation & Endometrial serous carcinoma & (29) \\
\hline & 36 & Mutation & Uterine CS & $(57)$ \\
\hline \multirow[t]{5}{*}{ CHD4 } & 56.4 & FS & Gastric cancer & $(30)$ \\
\hline & 55.7 & FS & Colorectal cancer & $(30)$ \\
\hline & 21 & Mutation & Endometrial serious carcinoma & $(28)$ \\
\hline & 7 & $\mathrm{OE}$ & Endometrial carcinoma & (29) \\
\hline & 4 & $\mathrm{OE}$ & Endometrial clear cell carcinoma & (29) \\
\hline \multirow[t]{2}{*}{$E Z H 2$} & 66 & $\mathrm{OE}$ & Ovarian cancer & $(36)$ \\
\hline & Unknown & $\mathrm{OE}$ & Melanoma, BC, lung cancer, cervical cancer & $(33,34)$ \\
\hline \multirow[t]{9}{*}{ MLL3 } & $<5$ & MS, NS, FS & Bladder carcinoma & (13) \\
\hline & 8 & MS, NS, FS & Prostate cancer & (14) \\
\hline & 13 & MS, NS, FS & Gastric adenocarcinoma & $(16)$ \\
\hline & 27 & Mutation & Uterine CS & $(57)$ \\
\hline & 14 & FS & Colorectal cancer & $(15)$ \\
\hline & 28.1 & FS & Gastric cancer & $(20)$ \\
\hline & 7.5 & FS & Colon cancer & $(20)$ \\
\hline & Unknown & Deletion & AML & $(21)$ \\
\hline & Unknown & MS, NS, FS & $\begin{array}{l}\text { BC, medulloblastoma, pancreatic cancer, } \\
\text { HCC, NSCLC }\end{array}$ & $(12,17-19)$ \\
\hline SMARCA4/ & 10 & GM, NS, FS & Lung adenocarcinoma & (49) \\
\hline \multirow[t]{6}{*}{ BRG1 } & 31.3 & GM, NS, FS & Lung large cell carcinoma & (49) \\
\hline & 36.4 & GM, NS, FS & Lung pleomorphic carcinoma & $(49)$ \\
\hline & 94 & GM, NS, FS & SCCOHT & $(26,45-47)$ \\
\hline & $<30$ & Mutation & NSCLC & (7) \\
\hline & $10-20$ & Mutation & $\begin{array}{l}\text { Melanoma, esophageal adenocarcinoma, } \\
\text { intraductal papillary mucinous neoplasms of } \\
\text { the pancreas }\end{array}$ & $(26)$ \\
\hline & Unknown & Mutation & $\begin{array}{l}\text { OSCC, rhabdoid tumor, mantle cell lymphoma, } \\
\text { Burkitt lymphoma, non-melanoma skin cancer }\end{array}$ & $(26)$ \\
\hline
\end{tabular}

MS, missense mutation; NS, nonsense mutation; FS, frameshift mutation; OE, overexpression; GM, germline mutation; HCC, hepatocellular carcinoma; BC, breast cancer; NSCLC, non-small cell lung carcinoma; AML, acute myeloid leukemia; OSCC, ovarian small cell carcinoma; CS, carcinosarcoma; SCCOHT, small cell carcinoma of the ovary hypercalcemic type; SMARCA4/BRG1, SWI/SNF-related, matrix-associated, actin-dependent regulator of chromatin, subfamily a, member 4; MLL3, mixed-lineage leukemia 3; EZH2, enhancer of zeste 2 polycomb repressive complex 2 subunit; $C H D 4$, chromodomain helicase, DNA-binding protein 4; ARID1A, AT-rich interaction domain $1 \mathrm{~A}$.

gene and that $A R I D I A$ mutation inactivates gene products through the aberrant chromatin remodeling associated with OCCC pathogenesis. ARIDIA encodes a component of the SWI/SNF complex, which regulates cell growth, controls cell cycle regulation and cell division and repairs DNA $(40,41)$.

Wiegand et al (42) detected an ARIDIA mutation in 55 $(46 \%)$ of 119 patients with OCCC and identified a deficit in $B A F 250 a$, a protein encoded by ARIDIA, in $36 \%$ of these patients (Table I). BAF250a gives specificity to the SWI/SNF complex and enables regulation of gene expression (22).
Furthermore, ARIDIA mutations and BAF250a deficits were identified in OCCC and adjacent endometriotic lesions, but not in distant lesions, which suggests that this mutation and resultant BAF250a deficit are events in the early stage of neoplastic transformation of endometriosis $(2,42)$. A previous study confirmed that an ARIDIA deficit was also an early phenomenon in endometriosis-associated ovarian cancer (EAOC) and endometriotic ovarian cysts, together with AKT protein activation and a histone $\mathrm{H} 2 \mathrm{~A}$ variant $(\gamma \mathrm{H} 2 \mathrm{AX})(43)$. An ARIDIA deficit has also been identified as a poor prognostic factor in 


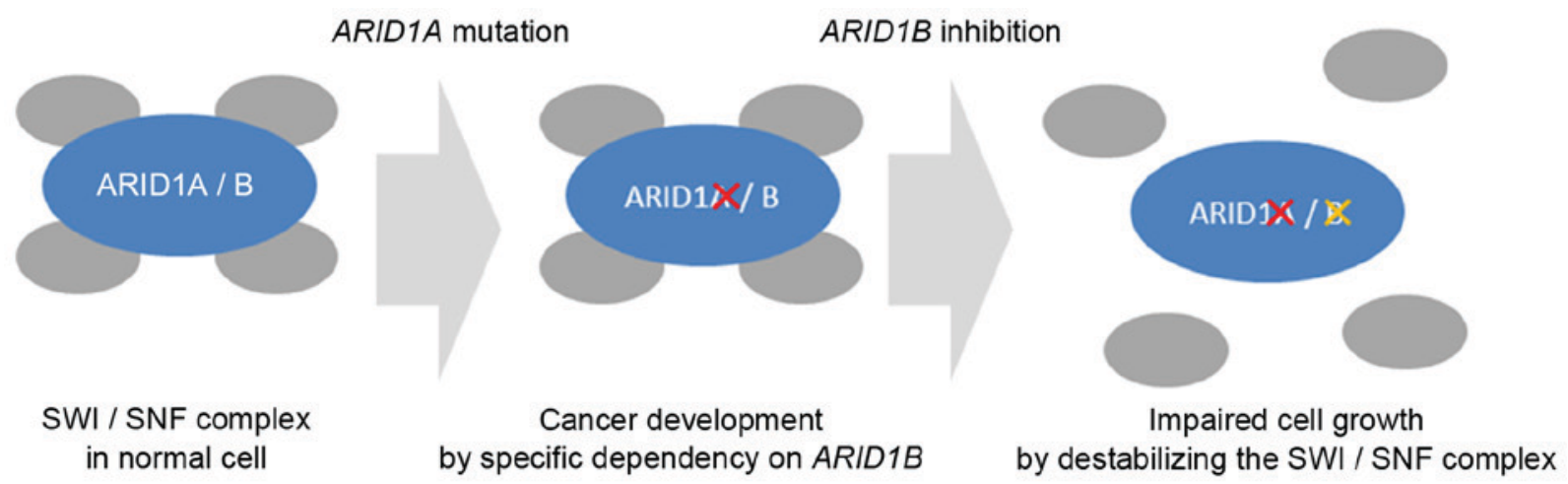

Figure 2. Coordinated carcinogenic effects of $A R I D 1 A / B$. If $A R I D 1 A$ is mutated, the $A R I D 1 B$ mechanism enhances cancer development. $A R I D I B$ inhibition destabilizes the SWI/SNF complex, which leads to inhibition of cell proliferation. ARID1B, AT-rich interaction domain 1A; SWI/SNF, switch/sucrose non-fermentable complex.

patients with stage I/II OCCC, and may be a useful biological marker for the prediction of prognosis (42).

Small cell carcinoma of the ovary, hypercalcemic type (SCCOHT) associated with hypercalcemia is a rare disease and is considered to be a rhabdoid tumor (26). SCCOHT is a poorly differentiated tumor associated with a poor prognosis that develops in young females (44). In an immunohistological study, Conlon et al (44) measured loss of SMARCA4 expression in $94 \%$ of patients with SCCOHT, whereas loss of SMARCA4 expression is usually identified in $<5 \%$ of patients with ovarian cancer (44). Therefore, these data are considered to be specific to SCCOHT (44). In SCCOHT, germline mutations have been revealed in one allele of SMARCA4, and expression is deleted due to an inactivating germline mutation and frameshift and nonsense mutations in the other allele (26,45-47). Rhabdoid tumors that develop in organs other than the ovary, including the kidney and brain, have germline and somatic expression of SMARCA4 (48). Immunostaining for the expression of SMARCA4 in tumor tissues of patients with lung cancer revealed downregulation of SMARCA4 in no patients with squamous cell carcinoma, in $10 \%$ with adenocarcinoma, in $31.3 \%$ with large cell carcinoma and in $36.4 \%$ with pleomorphic carcinoma (49), and somatic mutation and deletion of SMARCA4 are present in these types of cancer (26). SMARCA4 is a subunit of the BAF and PBAF complexes, and mutation and deletion produces incomplete complexes and abnormal subunits that may cause dysregulation of genes and induce disease (50).

\section{Aberrant chromatin remodeling and endometrial cancer}

Endometrial cancer includes endometrioid carcinoma and serous carcinoma, which is less common compared with endometrioid carcinoma and has a relatively poor prognosis (51). Almost all serous carcinomas are poorly differentiated type 2 endometrial cancer with myometrial, vascular and extrauterine invasion (51). In exome sequencing of endometrial serous carcinomas in 53 patients, Le Gallo et al (29) detected CHD4 mutations in $9(17 \%)$ cases, and identified mutation of chromatin remodeling genes, including ARIDIA, in 19 (36\%) (29) (Table I). Similarly, Zhao et al (28) identified CHD4 mutations in $11(21 \%)$ of 52 patients with endometrial serous carcinomas. CHD4 is a catalytic subunit of the NuRD complex that inhibits transcription and repairs DNA damage (52). CHD4 overexpression has also been revealed in $7 \%$ of endometrioid carcinomas and $4 \%$ of endometrial clear cell carcinomas, with half of $C H D 4$ mutations affecting the ATPase/helicase domain or helicase domain, which is suspected to be the cause of endometrial cancer (29).

Carcinosarcoma (CS) is an extremely rare gynecological disease with a poor prognosis (53). Histological results of CS demonstrate mixed epithelial carcinoma and non-epithelial sarcoma (53). CS occurs commonly in the uterine body, but has also been identified in the ovary, uterine cervix and vagina (54-56). The incidence in the United States is 2 per 100,000 , and the 5-year survival rates are $35-65 \%$ in the early stage and $\sim 10 \%$ in stage IV (53). In 22 patients with uterine CS, Jones et al (57) revealed ARIDIA mutations in 8 (36\%) cases, mutations of histone methyltransferase MLL3 in 6 (27\%) cases, mutations of speckle-type POZ protein (SPOP), which is involved in chromatin remodeling, in 3 (14\%) cases, and mutations of chromatin remodeling-associated genes in 14 (64\%) cases (57). ARIDIA serves an important role in the regulation of cell growth, and $M L L 3$ is a coactivator of tumor protein p53 (TP53), a tumor suppressor p53 gene $(2,58)$. SPOP is a transcriptional repressor of $\mathrm{p} 53$ via the bric-a-brac/tramtrack/broad complex protein (59). Jones et al (57) suggested that a specific tissue-type of uterine CS depends on aberrant chromatin remodeling. Therefore, a complete understanding of genetic mutations in this cancer will be useful for diagnosis, early detection and treatment.

\section{Therapy targeting aberrant chromatin remodeling}

Cancer cells with an ARIDIA deficit are highly sensitive to small molecule inhibitors in the PI3K/AKT signal transduction pathway. Therefore, drugs that inhibit this pathway are effective in patients with cancer with an ARIDIA deficit (60). Therapy targeting epigenetic regulatory mechanisms in cancer cells is also under development. Bitler et al (61) focused on the activity of EZH2, a methylation factor in cancer with ARIDIA mutation, and identified that proliferation of cells with an ARIDIA mutation was selectively inhibited by the administration of an EZH2 inhibitor. This suggests that EZH2 inactivation is a potential therapy for cancer with ARIDIA mutation, and EZH2 inhibition has been demonstrated to reduce the number 
of ovarian tumors with ARIDIA mutations in vivo. Therefore, pharmacological inhibition of EZH2 expression may be a therapeutic strategy for cancer with an ARIDIA mutation (61).

Guan et al (62) demonstrated that an ARIDIA in-frame mutation prevented ARID1A transport from the nucleus to the cytoplasm (62). The ARID1A protein was then degraded by the ubiquitin-proteasome system and was not available downstream, resulting in the onset of cancer. Thus, ARID1A degradation may be inhibited by targeting the ubiquitin-proteasome system in cells with an ARIDIA mutation, with potential recovery of the original cancer inhibitory effect (62).

$A R I D I B$ has recently been identified as an ARIDIA homolog (63). In cells with an ARIDIA deficit, ARIDIB is independently expressed and its proliferation is enhanced, which suggests that ARIDIA and ARIDIB may interact in promoting carcinogenesis. However, blocking the mechanism of ARIDIB in cells with an ARIDIA deficit destabilizes the SWI/SNF complex and inhibits cell proliferation. Therefore, $A R I D 1 B$ is also a therapeutic target in cancer with ARIDIA mutation (Fig. 2) (63). Immunohistochemical detection of ARIDIA expression may be a useful marker for the evaluation of malignancy, prognosis and treatment effect (64).

\section{Conclusion}

ARIDIA mutation is involved in gynecological cancer types such as OCCC and uterine cancer through the induction of aberrant chromatin remodeling and promotion of tumorigenesis. Germline mutations and epigenetic regulatory mechanisms, including chromatin remodeling, are involved in carcinogenesis. Therefore, there is a requirement for methods for identifying chromatin remodeling-associated gene mutations, including ARIDIA and BRGI, and for therapy targeting the carcinogenic mechanisms of aberrant chromatin remodeling.

\section{Acknowledgements}

The authors would like to thank Dr S. Fujiwara and Dr K. Hoshi (Keio University School of Medicine, Tokyo, Japan) for their assistance, and are grateful for support from the Keio Gijuku Academic Development Fund.

\section{References}

1. Weaver IC, Korgan AC, Lee K, Wheeler RV, Hundert AS and Goguen D: Stress and the emerging roles of chromatin remodeling in signal integration and stable transmission of reversible phenotypes. Front Behav Neurosci 11: 41, 2017.

2. Takeda T, Banno K, Okawa R, Yanokura M, Iijima M, Irie-Kunitomi H, Nakamura K, Iida M, Adachi M, Umene K, et al: ARID1A gene mutation in ovarian and endometrial cancers (Review). Oncol Rep 35: 607-613, 2016.

3. Clapier CR and Cairns BR: The biology of chromatin remodeling complexes. Annu Rev Biochem 78: 273-304, 2009.

4. Ronan JL, Wu W and Crabtree GR: From neural development to cognition: Unexpected roles for chromatin. Nat Rev Genet 14: 347-359, 2013

5. Huang B, Jiang $C$ and Zhang R: Epigenetics: The language of the cell? Epigenomics 6: 73-88, 2014

6. Alberts B, Johnson A, Lewis J, Raff M, Roberts K and Walter P: Molecular biology of the cell, 5th edition. Science: 215-216, 2008.

7. Wilson BG and Roberts CW: SWI/SNF nucleosome remodellers and cancer. Nat Rev Cancer 11: 481-492, 2011.
8. Oike T, Ogiwara H, Nakano T, Yokota J and Kohno T: Inactivating mutations in SWI/SNF chromatin remodeling genes in human cancer. Jpn J Clin Oncol 43: 849-855, 2013.

9. Jones S, Wang TL, Shih IeM, Mao TL, Nakayama K, Roden R, Glas R, Slamon D, Diaz LA Jr, Vogelstein B, et al: Frequent mutations of chromatin remodeling gene ARID1A in ovarian clear cell carcinoma. Science 330: 228-231, 2010.

10. Mayes K, Qiu Z, Alhazmi A and Landry JW: ATP-dependent chromatin remodeling complexes as novel targets for cancer therapy. Adv Cancer Res 121: 183-233, 2014.

11. Li WD, Li QR, Xu SN, Wei FJ, Ye ZJ, Cheng JK and Chen JP: Exome sequencing identifies an MLL3 gene germ line mutation in a pedigree of colorectal cancer and acute myeloid leukemia. Blood 121: 1478-1479, 2013.

12. Fujimoto A, Totoki Y, Abe T, Boroevich KA, Hosoda F, Nguyen HH, Aoki M, Hosono N, Kubo M, Miya F, et al: Whole-genome sequencing of liver cancers identifies etiological influences on mutation patterns and recurrent mutations in chromatin regulators. Nat Genet 44: 760-764, 2012.

13. Gui Y, Guo G, Huang Y, Hu X, Tang A, Gao S, Wu R, Chen C, Li X, Zhou L, et al: Frequent mutations of chromatin remodeling genes in transitional cell carcinoma of the bladder. Nat Genet 43: 875-878, 2011.

14. Lindberg J, Mills IG, Klevebring D, Liu W, Neiman M, Xu J, Wikström P, Wiklund P, Wiklund F, Egevad L and Grönberg H: The mitochondrial and autosomal mutation landscapes of prostate cancer. Eur Urol 63: 702-708, 2013.

15. Watanabe Y, Castoro RJ, Kim HS, North B, Oikawa R, Hiraishi T, Ahmed SS, Chung W, Cho MY, Toyota M, et al: Frequent alteration of MLL3 frameshift mutations in microsatellite deficient colorectal cancer. PLoS One 6: e23320, 2011.

16. Zang ZJ, Cutcutache I, Poon SL, Zhang SL, McPherson JR, Tao J, Rajasegaran V, Heng HL, Deng N, Gan A, et al: Exome sequencing of gastric adenocarcinoma identifies recurrent somatic mutations in cell adhesion and chromatin remodeling genes. Nat Genet 44: 570-574, 2012.

17. Liu P, Morrison C, Wang L, Xiong D, Vedell P, Cui P, Hua X, Ding F, Lu Y, James M, et al: Identification of somatic mutations in non-small cell lung carcinomas using whole-exome sequencing. Carcinogenesis 33: 1270-1276, 2012.

18. Ellis MJ, Ding L, Shen D, Luo J, Suman VJ, Wallis JW, Van Tine BA, Hoog J, Goiffon RJ, Goldstein TC, et al: Whole-genome analysis informs breast cancer response to aromatase inhibition. Nature 486: 353-360, 2012.

19. Biankin AV, Waddell N, Kassahn KS, Gingras MC, Muthuswamy LB, Johns AL, Miller DK, Wilson PJ, Patch AM, Wu J, et al: Pancreatic cancer genomes reveal aberrations in axon guidance pathway genes. Nature 491: 399-405, 2012.

20. Je EM, Lee SH, Yoo NJ and Lee SH: Mutational and expressional analysis of MLL genes in gastric and colorectal cancers with microsatellite instability. Neoplasma 60: 188-195, 2013.

21. Wu JN and Roberts CW: ARID1A mutations in cancer: Another epigenetic tumor suppressor? Cancer Discov 3: 35-43, 2013.

22. Trotter KW, Fan HY, Ivey ML, Kingston RE and Archer TK: The HSA domain of BRG1 mediates critical interactions required for glucocorticoid receptor-dependent transcriptional activation in vivo. Mol Cell Biol 28: 1413-1426, 2008.

23. Inoue H, Furukawa T, Giannakopoulos S, Zhou S, King DS and Tanese N: Largest subunits of the human SWI/SNF chromatin-remodeling complex promote transcriptional activation by steroid hormone receptors. J Biol Chem 277: 41674-41685, 2002.

24. Huang HN, Lin MC, Huang WC, Chiang YC and Kuo KT: Loss of ARID1A expression and its relationship with PI3K-Akt pathway alterations and ZNF217 amplification in ovarian clear cell carcinoma. Mod Pathol 27: 983-990, 2014.

25. Biegel JA, Busse TM and Weissman BE: SWI/SNF chromatin remodeling complexes and cancer. Am J Med Genet C Semin Med Genet 166C: 350-366, 2014.

26. Reisman D, Glaros S and Thompson EA: The SWI/SNF complex and cancer. Oncogene 28: 1653-1668, 2009.

27. Yamada M, Sato N, Ikeda S, Arai T, Sawabe M, Mori S, Yamada Y, Muramatsu M and Tanaka M: Association of the chromodomain helicase DNA-binding protein 4 (CHD4) missense variation p.D140E with cancer: Potential interaction with smoking. Genes Chromosomes Cancer 54: 122-128, 2015.

28. Zhao S, Choi M, Overton JD, Bellone S, Roque DM, Cocco E, Guzzo F, English DP, Varughese J, Gasparrini S, et al: Landscape of somatic single-nucleotide and copy-number mutations in uterine serous carcinoma. Proc Natl Acad Sci USA 110: 2916-2921, 2013. 
29. Le Gallo M, O'Hara AJ, Rudd ML, Urick ME, Hansen NF, O'Neil NJ, Price JC, Zhang S, England BM, Godwin AK, et al: Exome sequencing of serous endometrial tumors identifies recurrent somatic mutations in chromatin-remodeling and ubiquitin ligase complex genes. Nat Genet 44: 1310-1315, 2012.

30. Kim MS, Chung NG, Kang MR, Yoo NJ and Lee SH: Genetic and expressional alterations of CHD genes in gastric and colorectal cancers. Histopathology 58: 660-668, 2011.

31. Sasaki MM, Skol AD, Bao R, Rhodes LV, Chambers R, Vokes EE, Cohen EE and Onel K: Integrated genomic analysis suggests MLL3 is a novel candidate susceptibility gene for familial nasopharyngeal carcinoma. Cancer Epidemiol Biomarkers Prev 24: $1222-1228,2015$

32. Villacis RA, Miranda PM, Gomy I, Santos EM, Carraro DM, Achatz MI, Rossi BM and Rogatto SR: Contribution of rare germline copy number variations and common susceptibility loci in Lynch syndrome patients negative for mutations in the mismatch repair genes. Int J Cancer 138: 1928-1935, 2016.

33. Kim KH and Roberts CW: Targeting EZH2 in cancer. Nat Med 22: 128-134, 2016

34. Yang Q, Laknaur A, Elam L, Ismail N, Gavrilova-Jordan L, Lue J, Diamond MP and Al-Hendy A: Identification of polycomb group protein EZH2-mediated DNA mismatch repair gene MSH2 in human uterine fibroids. Reprod Sci 23: 1314-1325, 2016

35. Cai L, Wang Z and Liu D: Interference with endogenous EZH2 reverses the chemotherapy drug resistance in cervical cancer cells partly by up-regulating Dicer expression. Tumour Biol 37: 6359-6369, 2016

36. Lu C, Han HD, Mangala LS, Ali-Fehmi R, Newton CS, Ozbun L, Armaiz-Pena GN, Hu W, Stone RL, Munkarah A, et al: Regulation of tumor angiogenesis by EZH2. Cancer Cell 18 185-197, 2010

37. Crotzer DR, Sun CC, Coleman RL, Wolf JK, Levenback CF and Gershenson DM: Lack of effective systemic therapy for recurrent clear cell carcinoma of the ovary. Gynecol Oncol 105: 404-408, 2007.

38. Viganó P, Somigliana E, Chiodo I, Abbiati A and Vercellini P: Molecular mechanisms and biological plausibility underlying the malignant transformation of endometriosis: A critical analysis Hum Reprod Update 12: 77-89, 2006.

39. Nishikimi K, Kiyokawa T, Tate S, Iwamoto M and Shozu M: ARID1A expression in ovarian clear cell carcinoma with an adenofibromatous component. Histopathology 67: 866-871, 2015.

40. Nagl NG Jr, Wang X, Patsialou A, Van Scoy M and Moran E: Distinct mammalian SWI/SNF chromatin remodeling complexes with opposing roles in cell-cycle control. EMBO J 26: 752-763, 2007.

41. Weissman B and Knudsen KE: Hijacking the chromatin remodeling machinery: Impact of SWI/SNF perturbations in cancer Cancer Res 69: 8223-8230, 2009.

42. Wiegand KC, Shah SP, Al-Agha OM, Zhao Y, Tse K, Zeng T, Senz J, McConechy MK, Anglesio MS, Kalloger SE, et al ARID1A mutations in endometriosis-associated ovarian carcinomas. N Engl J Med 363: 1532-1543, 2010.

43. Itamochi H, Oumi N, Oishi T, Shoji T, Fujiwara H, Sugiyama T, Suzuki M, Kigawa J and Harada T: Loss of ARID1 A expression is associated with poor prognosis in patients with stage I/II clear cell carcinoma of the ovary. Int J Clin Oncol 20: 967-973, 2015.

44. Conlon N, Silva A, Guerra E, Jelinic P, Schlappe BA, Olvera N, Mueller JJ, Tornos C, Jungbluth AA, Young RH, et al: Loss of SMARCA4 expression is both sensitive and specific for the diagnosis of small cell carcinoma of ovary, hypercalcemic type. Am J Surg Pathol 40: 395-403, 2016.

45. Jelinic P, Mueller JJ, Olvera N, Dao F, Scott SN, Shah R, Gao J, Schultz N, Gonen M, Soslow RA, et al: Recurrent SMARCA4 mutations in small cell carcinoma of the ovary. Nat Genet 46 : 424-426, 2014

46. Ramos P, Karnezis AN, Craig DW, Sekulic A, Russell ML, Hendricks WP, Corneveaux JJ, Barrett MT, Shumansky K, Yang Y, et al: Small cell carcinoma of the ovary, hypercalcemic type, displays frequent inactivating germline and somatic mutations in SMARCA4. Nat Genet 46: 427-429, 2014.
47. Witkowski L, Carrot-Zhang J, Albrecht S, Fahiminiya S, Hamel N, Tomiak E, Grynspan D, Saloustros E, Nadaf J, Rivera B, et al: Germline and somatic SMARCA4 mutations characterize small cell carcinoma of the ovary, hypercalcemic type. Nat Genet 46: 438-443, 2014.

48. Schneppenheim R, Frühwald MC, Gesk S, Hasselblatt M, Jeibmann A, Kordes U, Kreuz M, Leuschner I, Martin Subero JI, Obser T, et al: Germline nonsense mutation and somatic inactivation of SMARCA4/BRG1 in a family with rhabdoid tumor predisposition syndrome. Am J Hum Genet 86: 279-284, 2010

49. Yoshimoto T, Matsubara D, Nakano T, Tamura T, Endo S, Sugiyama Y and Niki T: Frequent loss of the expression of multiple subunits of the SWI/SNF complex in large cell carcinoma and pleomorphic carcinoma of the lung. Pathol Int 65: 595-602, 2015.

50. Helming KC, Wang X and Roberts CW: Vulnerabilities of mutant SWI/SNF complexes in cancer. Cancer Cell 26: 309-317, 2014.

51. Sherman ME: Theories of endometrial carcinogenesis: A multidisciplinary approach. Mod Pathol 13: 295-308, 2000.

52. Polo SE, Kaidi A, Baskcomb L, Galanty Y and Jackson SP: Regulation of DNA-damage responses and cell-cycle progression by the chromatin remodelling factor CHD4. EMBO J 29: 3130-3139, 2010.

53. Duman BB, Kara IO, Günaldi M and Ercolak V: Malignant mixed Mullerian tumor of the ovary with two cases and review of the literature. Arch Gynecol Obstet 283: 1363-1368, 2011.

54. Sharma NK, Sorosky JI, Bender D, Fletcher MS and Sood AK: Malignant mixed mullerian tumor (MMMT) of the cervix. Gynecol Oncol 97: 442-445, 2005.

55. Ahuja A, Safaya R, Prakash G, Kumar L and Shukla NK: Primary mixed mullerian tumor of the vagina - a case report with review of the literature. Pathol Res Pract 207: 253-255, 2011.

56. George EM, Herzog TJ, Neugut AI, Lu YS, Burke WM, Lewin SN, Hershman DL and Wright JD: Carcinosarcoma of the ovary: Natural history, patterns of treatment, and outcome. Gynecol Oncol 131: 42-45, 2013.

57. Jones S, Stransky N, McCord CL, Cerami E, Lagowski J, Kelly D, Angiuoli SV, Sausen M, Kann L, Shukla M, et al: Genomic analyses of gynaecologic carcinosarcomas reveal frequent mutations in chromatin remodelling genes. Nat Commun 5: 5006, 2014

58. Lee J, Kim DH, Lee S, Yang QH, Lee DK, Lee SK, Roeder RG and Lee JW: A tumor suppressive coactivator complex of p53 containing ASC-2 and histone H3-lysine-4 methyltransferase MLL3 or its paralogue MLL4. Proc Natl Acad Sci USA 106 8513-8518, 2009.

59. Kwon JE, La M, Oh KH, Oh YM, Kim GR, Seol JH, Baek SH, Chiba T, Tanaka K, Bang OS, et al: BTB domain-containing speckle-type POZ protein (SPOP) serves as an adaptor of Daxx for ubiquitination by Cul3-based ubiquitin ligase. J Biol Chem 281: 12664-12672, 2006.

60. Samartzis EP, Gutsche K, Dedes KJ, Fink D, Stucki M and Imesch P: Loss of ARID1A expression sensitizes cancer cells to PI3K- and AKT-inhibition. Oncotarget 5: 5295-5303, 2014.

61. Bitler BG, Aird KM, Garipov A, Li H, Amatangelo M, Kossenkov AV, Schultz DC, Liu Q, Shih IeM, ConejoGarcia JR, et al: Synthetic lethality by targeting EZH2 methyltransferase activity in ARID1A-mutated cancers. Nat Med 21: 231-238, 2015.

62. Guan B, Gao M, Wu CH, Wang TL and Shih IeM: Functional analysis of in-frame indel ARID1A mutations reveals new regulatory mechanisms of its tumor suppressor functions. Neoplasia 14: 986-993, 2012.

63. Helming KC, Wang X, Wilson BG, Vazquez F, Haswell JR, Manchester HE, Kim Y, Kryukov GV, Ghandi M, Aguirre AJ, et al: ARID1B is a specific vulnerability in ARID1A-mutant cancers. Nat Med 20: 251-254, 2014.

64. Nagymanyoki Z, Mutter GL, Hornick JL and Cibas ES: ARID1A is a useful marker of malignancy in peritoneal washings for endometrial carcinoma. Cancer Cytopathol 123: 253-257, 2015 